\title{
A Defense of Sociobiology
}

\author{
K.R. FosteR \\ Center for Systems Biology, Harvard University, Cambridge, Massachusetts 02138 \\ Correspondence: kfoster@cgr.harvard.edu
}

\begin{abstract}
To counter recent claims that sociobiology is in disarray or requires reformulation, I discuss the semantics, theory, and data that underlie the field. A historical perspective is used to identify the cause of current debates. I argue that semantic precision is required in discussing terms such as kin selection, group selection, and altruism, but once care is taken, the objections to the unity of theoretical sociobiology largely evaporate. More work is required, however, to understand group adaptation, which might be taken to be the process of optimizing phenotypes that is driven by group, rather than individual, context. From the empirical perspective, the eusocial insects with their fixed division between work and reproduction are often a sounding board in discussions. Here, one finds clear evidence for the role of kin selection and relatedness in both the origin of eusociality and its maintenance. Data from other systems including the social vertebrates, microorganisms, and even plants also support the role of relatedness and particularly family life in the evolution of cooperation and altruism. These data, however, in no way invalidate the claim that group selection is also a central process in social evolution and I discuss the empirical evidence for group selection. The foundations of sociobiology are solid and the future should build on these foundations. Exciting new areas include the importance of community and species-level selection in evolution and elucidating the molecular mechanisms that underlie social traits.
\end{abstract}

Kinship plays a minor role [in social evolution], and this has been why kinship theory has produced so little over four decades in important predictions. In fact, it has made virtually none.

\section{E.O. Wilson (pers. comm.)}

The first Quantitative Biology Symposium to celebrate Darwin is perhaps best known for Mayr's (1960) strong attack on theoretical population genetics, which Mayr colorfully criticized for reducing the evolutionary process to the "adding of certain beans to a beanbag and the withdrawing of others." He continued: "[Fisher, Wright and Haldane] have worked out an impressive mathematical theory of genetical variation and evolutionary change. But what, precisely, has been the contribution of this mathematical school to the evolutionary theory, if I may be permitted to ask such a provocative question?" It was this essay, along with one of Mayr's books, that led Haldane (1964) to later write the aptly named "A Defense of Beanbag Genetics" (Haldane did not attend the 1960 meeting because he was refused a U.S. visa).

I was privileged to attend, 50 years later, the second Quantitative Biology Symposium to celebrate Darwin. One might ask whether anything similarly controversial to Mayr's attack on population genetics has occurred. At least for me, there was an uncanny resemblance in the paper of E.O. Wilson, which was a resounding assault on the theoretical foundations of sociobiology. The above opening quotation was followed by argument for an alternative view of social evolution that instead of kinship appeals to a mix of preadaptation, emergent properties, and group selection. For students of social evolution, this assault will come as no surprise but part of a continuing theme in the recent writing of Wilson and others (Wilson
2005, 2008b; Wilson and Holldobler 2005; Wilson and Wilson 2007). But for biologists from other disciplines, it may be shocking to hear one of the founders of sociobiology (Wilson 1975b) attempt to so strongly undermine its basis.

The goal of this chapter is to offer a defense of modern sociobiology. My discussion follows the emphasis of Wilson's original book Sociobiology: "This brings us to the central theoretical problem of sociobiology: How can altruism, which by definition reduces personal fitness, possibly evolve by natural selection?" (Wilson 1975b, p. 3 ). However, I should note up front that sociobiology now encompasses additional topics that I will largely neglect, including parent-offspring conflict (Trivers 1974), intragenomic conflicts (Hurst et al. 1996; Burt and Trivers 2006), classical game theory (Trivers 1971; Maynard Smith and Price 1973; Axelrod and Hamilton 1981; Doebeli and Hauert 2005), and perhaps even sexual selection (Darwin 1859). I seek to put the recent comments of Wilson and others into a historical context and, hopefully, offer some reassurance that the appearance of ongoing controversy is mostly illusory. Accordingly, I argue that the theoretical foundations of sociobiology are solid and that there are extensive data that support this position. Finally, I attempt to identify a few future questions that might build on this foundation. This is not the first time that I (Foster 2006; Foster et al. 2006a,b) or others (Queller 1992; Dugatkin and Reeve 1994; Reeve and Keller 1999; Lehmann and Keller 2006; Lehmann et al. 2007; West et al. 2007) have attempted to do this. Nevertheless, misunderstandings in social evolution continue to abound and our considerable progress is continually troubled by a confusion of terms and debates. This, I hope, offers some justification for what will follow. 


\section{THE HISTORY}

There will also, no doubt, be indirect effects in cases in which an animal favours or impedes the survival or reproduction of its relatives... . Nevertheless such indirect effects will in very many cases be unimportant...

Fisher (1930)

Sociobiology, in name, barely existed at the time of the first Cold Spring Harbor Symposium on Darwinism, but discussions of social behavior and its evolution by natural selection began much earlier. In Darwin's writing, it is easy to find the traces of the two key concepts upon which modern sociobiology was founded-group selection and kinship - the same concepts that continue to fuel the fires of controversy. Indeed, in explaining one of the most striking examples of social behavior, the effectively sterile workers of social insects (Fig. 1), Darwin appealed to both family life and natural selection acting at the level of the insect colony (Gardner and Foster 2008). This blend of kinship and grouping in explanations of social behav-
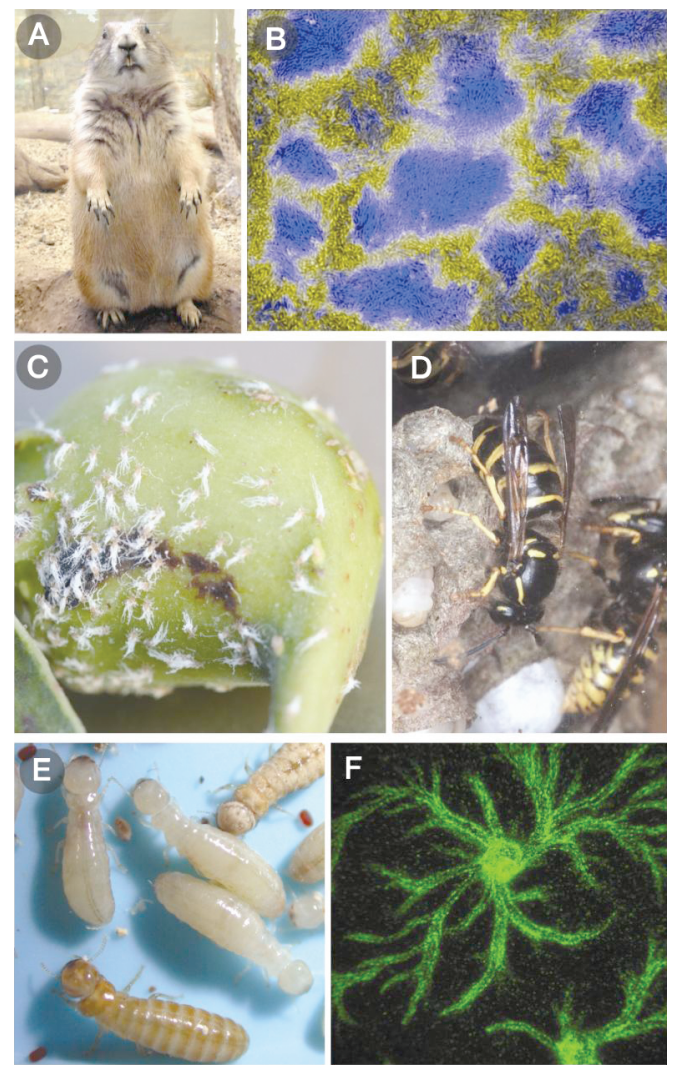

Figure 1. A selection of the social species discussed: a prairie dog $(A)$, a biofilm of the bacterium Pseudomonas aeruginosa $(B)$, and the gall-dwelling aphid Pemphigus obesinymphae $(C)$. When disturbed, soldier aphids emerge and attack intruders. $(D)$ A worker laying a male-destined egg in the social wasp Dolichovespula saxonica. (E) The termite Cryptotermes secundus, in which a gene required for reproductive suppression of the workers has been described (Korb et al. 2009). (F) Aggregation of fluorescently labeled cells in the slime mold or social amoebae D.discoideum. (Images created by the author, except $C$ by Patrick Abbot, and $E$, by Judith Korb.) ior continued into the early 20 th century with a near-modern perspective seen relatively early on: "The instincts of the workers can be kept up to the mark by natural selection. Those fertile females whose genes under worker diet do not develop into workers with proper instincts will produce inefficient hives; such communities will go under in the struggle for existence, and so the defective genes will be eliminated from the bee germ-plasm." (Wells et al. 1929)

It is also possible to find contemporaneous examples that play down the importance of kinship. Although recognizing its theoretical potential to affect evolution, for example, Fisher (1930) considered kinship to be an unimportant detail in the process of natural selection. Concordantly, two features are notable of the era that preceded the rise of sociobiology: a lack of controversy surrounding social evolution and, more importantly, a lack of interest. These features extend to 1959 and the Cold Spring Harbor Symposium, where despite a session entitled "Ecological systems and social organizations," there is little evidence of the modern interest in the social evolution, with its emphasis on cooperation and competition (Fig. 2). Soon after, however, the intellectual landscape began to change with two key publications - one now famous, the other infamous - which set the stage for the coming debates.

Infamy was to result for the book of Wynne-Edwards (1962) entitled Animal Dispersal in Relation to Social Behaviour. Replete with examples, this book made frequent use of arguments from population-level advantage to explain animal behaviors. Territoriality and dominance hierarchies, it was suggested, evolve to limit animal populations and to prevent the overuse of resources that might threaten the population with extinction. The problem with this particular brand of reasoning was rapidly

\section{EFFECT ON RECIPIENT}

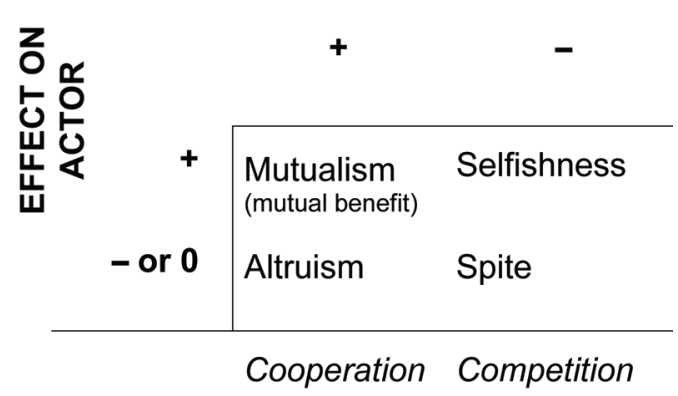

Figure 2. A social behavior is defined here as one that has a fitness effect on another individual. The four types of social actions are classified based on their average effect on the direct fitness (lifetime personal reproduction) of the actor and recipient. Altruism and spite can have either no fitness effect or a negative fitness effect on the actor. Behaviors that have no fitness effect on the recipient are not considered (based on Hamilton 1964). The $+/+$ interaction is typically called mutualism. However, mutualism is also used to mean a case where the actor helps the recipient and the recipient helps the actor. What the table defines, however, is when the actor helps the recipient and the actor helps himself. For this reason, West et al. (2007) renamed this case "mutual benefit." 
picked up upon. Notably, Williams (1966) devoted a chapter to such "group selection" logic and argued strongly that it will typically have a weak effect on the evolutionary process. The logic is as follows. Consider a population of red grouse in which all individuals are territorial because this keeps population density low and heather abundant. A mutant nonterritorial grouse would do very well here because his offspring will pack themselves in and rapidly outnumber the resident birds. Over time, therefore, territoriality should be lost as the nonterritorial birds spread. Of course, territoriality does not really evolve to keep population density low but to allow males to attract females, which makes it evolutionarily stable. Nevertheless, the hypothetical example is illustrative: Evolutionary explanations that only consider the group or population level are incomplete. One must also always consider the possibility of natural selection at the level of the individual and sometimes the organelle or gene. This lesson may seem trivial to the modern evolutionary biologist. With the rise of evolutionary thinking in new disciplines, however, so rises the specter of uncritical group-level thinking. It is, for example, still seen in my own field of microbiology (West et al. 2006; Foster 2010).

Relative fame would result for Hamilton following the publication of back-to-back papers in the Journal of Theoretical Biology (Hamilton 1964); a briefer version of the same ideas was published a year earlier (Hamilton 1963). The result of Hamilton's Ph.D. thesis, these papers set out an argument for the evolution of altruistic behaviors "which are on average to the disadvantage of the individuals possessing them" (Fig. 2) (Hamilton 1964). Unlike William's book, Hamilton was not particularly motivated by Wynne-Edwards' book (1962), which he cited but only for a few examples. Hamilton, it seems, worked in relative isolation. Indeed, his autobiographical writings suggest that he received little support in his chosen topic from senior colleagues (Hamilton 1996). Nevertheless, he determinedly ploughed on and the papers that resulted are among the most cited in evolutionary biology. At their heart was family life, so much so that MaynardSmith christened the resulting theory "kin selection" in a Nature paper (Maynard Smith 1964) somewhat controversially published while Maynard Smith was reviewing Hamilton's Journal of Theoretical Biology papers. Hamilton had termed his theory "inclusive fitness."

Hamilton's key insight was that evolution by natural selection is driven not only by effects on a focal individual's own reproduction (direct fitness), but also by any effects on the reproduction of individuals that are genetically similar (indirect fitness). More precisely, indirect fitness effects occur when the actor and recipient of a social action have an above average (or below average) probability of sharing alleles at variable loci. Helping or harming relatives will affect an actor's fitness in proportion to the genetic similarity between actor and recipient, where "similarity" is measured relative to the population average. This is genetic relatedness. Only by accounting for such indirect effects, as well as direct effects, can the selective effects of a behavior be understood. It is in this sense that Hamilton's fitness accounting scheme is "inclusive." A complementary fitness accounting scheme, also first envisioned by Hamilton, that again separates direct and indirect effects is that of "neighbor-modulated" fitness. The only difference to inclusive fitness is that instead of calculating the effects from a focal individual to its reproduction and that of neighbors, fitness accounting is done all in terms of effects to the focal individual's reproduction from itself and its neighbors. The difference is largely just a choice in accounting, however, and the two approaches should result in identical predictions (Frank 1998; Wenseleers et al. 2010).

The publication of Wynne Edward's book and Hamilton's papers was the spark for the controversy that continues today. Reaction to Hamilton's papers was relatively slow, but by the 1970s, there was an ever-polarizing opinion against arguments based on group- and populationlevel selection. This view was crystallized in the success of Dawkin's "The Selfish Gene" (1976), which to a large extent is based on Hamilton's insights. Ironically, this crystallization occurred several years after Hamilton himself had been convinced of the validity and importance of group selection in evolution. Sometime before 1970, in a letter from one solitary eccentric to another, one George Price wrote to Hamilton to explain that he had discovered a new way to view the evolutionary process (Hamilton 1996; Schwartz 2000). What would later become known as the Price equation naturally led to a way to partition the evolutionary process into effects at the level of the individual and the level of the group. Seeing this, Hamilton realized that natural selection above the level of the individual must occur and contribute to the evolutionary process. Price would soon after make a second major contribution to evolutionary biology by introducing ideas from economic game theory, although it was down to Maynard Smith and others to actually publish and popularize the idea (Maynard Smith and Price 1973; Axelrod and Hamilton 1981; Maynard Smith 1982).

By 1974, Price would be dead. It appears that Price was so affected by his discoveries to believe them miraculous. He turned to a religious selflessness that culminated in suicide. Filled with regret, Hamilton (1996) later recalled of Price: "I am pleased to say that, amidst all else that I ought to have done and did not do, some months before he died I was on the phone telling him enthusiastically that through a "group-level" extension of his formula I now had a far better understanding of group selection acting at one level or at many than I had ever had before." Hamilton published his insights on group selection in 1975 and, in the same year, D.S. Wilson published the first of his many papers that argue for the validity of group selection as a process in evolution (Hamilton 1975; Wilson 1975a). What had changed since the resounding attack on group selection by Williams and others in the 1960s? Opinions differ on this and indeed on whether anything substantial had changed (West et al. 2007, 2008; Wilson 2008a). What is clear, however, was that group selection now had a theoretical basis that showed it to be quite compatible with inclusive fitness or kin selection thinking. With this came the key observation that group selection can work as long as there is some degree of 
genetic differentiation among groups. That is, members of groups must be more genetically similar to their group average than to other groups, otherwise natural selection has no variation on which to act. Put another way, at the level of the group, there must be genetic relatedness (more on what relatedness exactly means here below). By 1975 then, kin and group selection had been combined, at least in some minds and the controversy was over (see next page). Or at least it should have been. In fact, we still face high-profile claims from one side that group selection as a process cannot work (Alcock 2005) and from the other that we do not need kinship-based thinking but rather a group selection framework (Wilson 2005, 2008b; Wilson and Holldobler 2005; Wilson and Wilson 2007), as again argued at Cold Spring Harbor (E.O. Wilson, pers. comm.). How can this be? There are of course many reasons both sociological and scientific, but, as is so often the case, at the heart of the confusion lies semantics. A necessary evil, therefore, in any defense of sociobiology is to discuss the semantics - as well as the theory and data - that speak to the debates.

\section{THE SEMANTICS AND THE THEORY}

\section{Kin Selection}

Either you are some kind of amnesiac capable of unconsciously fabricating an anecdote harmful to the reputation of a fellow scientist or else you are a person capable of fabricating such an anecdote conciously [sic] as part of an attempt to avoid the discomfort of admitting intellectual indebtedness to a younger man. The first supposition is the best that I can think of you.

Letter from Hamilton to Maynard Smith (19 October 1977)

Perhaps the single most inflammatory term in modern sociobiology is the "kin" of kin selection. Hamilton was never happy with Maynard Smith's term, and they crossed swords in print and in private on several issues (Schwartz 2000). For many years, Hamilton felt Maynard Smith was trying to diminish the impact of his work. This includes the belief that Maynard Smith fabricated an anecdote about Haldane (Maynard Smith 1975) in order to create a false precedent on kin selection. Haldane had in fact published his brief thoughts on the subject (Haldane 1955) and, strangely, in an article that Hamilton cited (Hamilton 1964). Hamilton would later apologize, and, anyway, his opinion on the term "kin selection" was no match for its catchiness. To this day, it is typically used in place of inclusive fitness in discussions of Hamilton's work. The result has been an emphasis on kinship in discussions of Hamilton's work rather than the more general concept of genetic relatedness. This seemingly minor distinction proves to be critical in discussions of whether kin and group selection are equivalent. Why is this? The answer lies in the fact that kinship - being a member of the same family - is only one way to generate an above-average genetic similarity among individuals (relatedness). There are other ways, the most celebrated being the concept of a green beard gene. So named by Dawkins (1976) but dreamt up by
Hamilton (1964), this is the statement that alleles that promote the energetically costly helping of others can spread if they can both identify themselves in other individuals and preferentially direct help to those individuals. Greenbeards are less likely to drive stable cooperation than kinship because of the potential for "falsebeard" individuals who do not help others but retain the signal to receive help (Gardner and West 2010). Importantly for the theory, however, greenbeards illustrate that there can be indirect fitness effects even if interacting individuals are not kin in the sense of being family relatives. This thought experiment, and the subsequent discovery of green beards in multiple species (Keller and Ross 1998; Queller et al. 2003; Smukalla et al. 2008), illustrates that Hamilton's (1964) kin selection is possible whether genetic associations occur through kinship or through other means (Foster et al. 2006a). Some proponents of group selection, however, like to take the narrow definition of kin selection that only includes family groups (Wilson and Holldobler 2005). From there, one can argue that because relatedness can occur without strict kinship, evolution can occur by group selection without kin selection, e.g., via green beard genes. If one does take a narrow definition of kin selection, this claim does follow, but hopefully, it is also clear that this is not a deep objection to the unity of sociobiology.

A more sophisticated objection to the equivalency of group and kin selection comes from the observation that group selection can occur in randomly formed groups of unrelated individuals (Wilson 1990). Consider, for example, a hypothetical Prairie dog group (known as a "town") containing unrelated individuals in which a particular Prairie dog's survival depends on the digging of tunnels that allow the group to forage. It may well pay the Prairie dog to expend her energy to dig tunnels that benefit all members of the town - what can be called a "group trait"- because this has a feedback benefit on her survival. This constitutes a form of group selection for digging behavior but does not require genetic relatedness of any sort among the members of the town. Does this run contrary to kin selection thinking? To answer this, we must first separate two possible goals that are often conflated. The first is the goal of identifying differences between kin selection and group selection as processes, and the other is identifying differences between kin and group selection as theoretical frameworks. In answer to the first goal, because the individuals in the group are unrelated by any definition, one can argue that there is indeed no kin selection, meaning the process, in this scenario. However, for the theory, the critical point is that our focal Prairie dog is a recipient of the benefits of digging (as well as is the rest of the town). She should be, hence, included in the calculation of relatedness toward recipients, which means that positive relatedness from actor to recipients does have a role simply because the Prairie dog is related to herself. As such, the example is understood equally well from a kin selection or group selection perspective. One just has to be careful about how relatedness is calculated. Again, whether or not one wants to call this kin selection a process is a matter of semantic preference, but, again, it should be clear that there is little reason for this to be a point for continued debate. What can 


\section{THE DIFFERENT WAYS OF ANALYZING SOCIAL EVOLUTION}

To more formally illustrate the different methods for analyzing social evolution, I reproduce here Box 1 (with minor modifications) from Wenseleers et al. (2010), which is a more careful discussion of social evolution theory than found here. In this box, we analyze Frank's $(1994,1995)$ "tragedy of the commons" model, which has been successfully applied to a variety of biological problems (see, e.g., Frank 1994; Foster 2004; Wenseleers et al. 2004a,b). The tragedy of the commons states that each individual would gain by claiming a greater share of the local resources, but that the group would perish if all local resources were exhausted (Hardin 1968). Frank's model captures this tension between group and individual interests by writing individual fitness as

$$
w_{i j}=\left(1-g_{i}\right) \cdot\left(g_{i j} / g_{i}\right),
$$

where $g_{i j}$ and $g_{i}$ are the individual and group mean breeding values for a behavior that causes individuals to selfishly grab local resources (normalized to go from 0 to 1 ). In this simple model, $\left(1-g_{i}\right)$ is the group's productivity, which declines as the average level of selfishness $g_{i}$ increases (we assume linearly, but this can easily be relaxed) (Foster 2004), and $g_{i j} / g_{i}$ is the relative success of an individual within its group. Similarly, we can write the fitness of other members in the group as

$$
w^{\prime}=\left(1-g_{i}\right) \cdot\left(g^{\prime} / g_{i}\right),
$$

where $g^{\prime}$ is the average level of selfishness of these other individuals. Note that with a group size of $n, g_{i}=(1 / n) g_{i j}+((n-1) /$ $\left.n) g^{\prime}\right)$ ), which we can substitute into Equations B1 and B2.

From a neighbor-modulated fitness perspective, a rare mutant that is slightly more selfish than the wild type is favored when

$$
\partial w_{i j} / \partial g_{i j}+\partial w_{i j} / \partial g^{\prime} \cdot r>0
$$

because an individual carrying the mutation would experience a direct $\operatorname{cost} \partial w_{i j} / \partial g_{i j}$ but, with probability $r$, be paired with group mates that also carry the mutation, hence resulting in a return benefit of $\partial w_{i j} / \partial g^{\prime}$.

Similarly, from an inclusive fitness perspective, a rare, slightly more selfish mutant would be favored when

$$
\partial w_{i j} / \partial g_{i j}+(n-1) \cdot \partial w^{\prime} / \partial g_{i j} \bullet r>0
$$

because an individual actor that expressed the mutant behavior would experience a direct cost $\partial w_{i f} / \partial g_{i j}$ but impose a cost of $\partial w^{\prime} / \partial g$ to each of its $n-1$ group mates, which are related by $r$ to itself. It is easily checked that because $\partial w^{\prime} / \partial g=$ $\left(\partial w / \partial g^{\prime}\right)\left(g^{\prime} / g_{i j}\right) /(n-1)$ and because mutations have small effect so that $g^{\prime} \cong g_{i j},(n-1) \cdot \partial w^{\prime} / \partial g_{i j}=\partial w_{i j} / \partial g^{\prime}$, inequalities B3 and B4 are therefore equivalent.

From a levels of selection perspective, selection would be partitioned into components that are due to the differential fitness of groups with different mean levels of selfishness and the differential success of more versus less selfish individuals within groups. Specifically, if we call $G$ group productivity and $I$ individual fitness relative to other group members, we have $G=w_{i}=\left(1-y_{i}\right), I=w_{i j} / w_{i}=y_{i j} / y_{i}$ and individual fitness $w_{i j}=G \cdot I$. A more selfish mutant will be selected for when positive within-group selection balances with negative among-group selection:

$$
\partial w_{i j} / \partial g_{i j} \cdot(1-R)>-\partial w_{i} / \partial g_{i} \bullet R,
$$

where $R$ and $1-R$ are proportional to the between-group and within-group genetic variances and $R=(1 / n)+((n-1) / n) \bullet r$. Note that the among-group and within-group selection components are also sometimes calculated in an equivalent way as $\partial w_{i j} / \partial G \bullet d G / d g_{i j}=I \bullet \partial G / \partial g_{i} \bullet d g_{i} / d g_{i j}=I \bullet \partial G / \partial g_{i} \cdot R$ and $\partial w_{i j} /$ $\partial I \bullet d I / d g_{i j}=G \bullet\left(\partial I / \partial g_{i j} d d g_{i j} / d g_{i j}+\partial I / \partial g_{i} \cdot d g_{i} / d g_{i j}\right)=G \bullet\left(\partial I / \partial g_{i j}\right.$ $+\partial I / \partial g_{i} \cdot R$ ) (cf. Ratnieks and Reeve 1992), which has the advantage that these only require the calculation of derivatives and do not involve variances.

Differently still, using contextual analysis, we can see that a more selfish mutant can invade when

$$
\beta_{w_{i} g_{i j} \cdot g_{i}}+\beta_{w_{g} g_{e} g_{j}} \cdot R>0 .
$$

Where the $\beta$ terms are the partial regression of individual genotype on fitness holding group genotype constant, and the partial regression of group genotype on individual fitness holding individual fitness constant. Reassuringly, the evaluation of the partial derivatives in Equations B3-B6 for the case where $g_{i j} \cong g^{\prime} \cong g_{i} \cong \bar{g}$ shows that no matter how we partition social evolution, the net selective effect is the same and that an equilibrium is reached when $g^{*}=1-R$, i.e., the equilibrium level of selfishness decreases as relatedness increases. At this equilibrium, no mutant that behaves slightly differently can invade in the population (Maynard Smith 1982). In addition, it can be checked that the equilibrium is evolutionarily stable, i.e., a fitness maximum, because the derivatives of the above fitness gradients $D$ (Equations B3-B6) with respect to $g_{i j}$ are negative. Finally, an additional stability criterion, convergence stability, specifies whether the equilibrium is an attractor or not, and is therefore attainable, and requires that the fitness gradient is positive when evaluated for $g$ slightly below $g^{*}$ and negative when $g$ is slightly higher than $g^{*}$. Formally, this occurs when

$$
\left.\frac{\partial D}{\partial g^{*}}\right|_{g_{y}=g^{\prime}=g_{i}=g^{*}}
$$

(Eshel and Motro 1981; Taylor 1996).

A strategy that is simultaneously evolutionarily and convergence stable is termed a continuously stable strategy (CSS) (Eshel 1983; Christiansen 1991), and it can be checked that the equilibrium in our example is indeed a CSS. Strategies that are convergence stable but not evolutionarily stable, however, are also possible, and can lead to disruptive selection and evolutionary branching (Metz et al. 1992; Geritz et al. 1998). Evolutionary branching points are interesting, because they provide us with the conditions under which continuous or mixed strategy ESSs (evolutionarily stable strategies) would be expected to evolve toward discrete strategy ESSs (see, e.g., Doebeli et al. 2004). 
be, and is, still debated is whether kin selection or group selection theory is better for ease of calculation and making testable predictions (West et al. 2007, 2008; Wilson 2008a). Here, publication volume and impact seem to side with kin selection theory, but their utility will ultimately depend on the question at hand (Foster 2006).

The issue of distinguishing between theoretical framework and process is also raised by Nowak's Five Rules for the Evolution of Cooperation, which therein are kin selection, group selection, network reciprocity, reciprocal altruism, and indirect reciprocity (Nowak 2006). These five "rules" represent a mixture of both framework and process. For most biological problems, including the evolution of Hamilton's altruism (see Fig. 2), kin selection, group selection, and network reciprocity are simply different ways of conceptualizing the same processes (Lehmann et al. 2007a,b). In contrast, reciprocal altruism and indirect reciprocity are processes that are distinct from each other, as they are from the other three rules (although reciprocity can be thought of in terms of networks). A way to avoid conflating equivalent descriptions is to take a real biological problem, for example, the evolution of worker behavior in a wasp nest, and ask which of the frameworks can be applied to explain it. For the wasps, one can use kin selection, group selection, or an interacting network of wasps, but the two forms of reciprocity would not apply.

\section{Altruism}

A related bone of contention is whether the evolution of altruism strictly requires kin selection or whether it can occur with group selection alone. Answers in favor of the former (Hamilton 1964; Foster et al. 2006a) and the latter (Wilson 1990; Fletcher and Doebeli 2009) exist in the literature, with the answer again depending on how one defines altruism and indeed kin selection. To proceed, I must assume that the reader accepts that "altruism" can be defined in terms of evolutionary fitness at all. It is common to hear the lay person, humanities scholar, and even some scientists object to a fitness-based definition of altruism, arguing instead that altruism refers to an actor's conscious intention to do good. To such understandable objections, I note only that the founding discussions of the definition of altruism - shortly after its invention by Auguste Comte-include both intentionbased and fitness-based usage (Dixon 2008; Foster 2008). The modern preference for the intentional definition is just that, a preference only.

Accepting a fitness-based definition of altruism, however, only leads to further choices. Here, I defer to the primacy of Hamilton's role in sociobiology. Hamilton defined altruism as an action that benefits others but will, on average, decrease the lifetime personal reproductive fitness of the actor (Fig. 2). This definition sees altruism in the social insect worker that could reproduce but instead raises her mother's offspring. However, it denies altruism in cases where there are feedback benefits to an action that eventually increase personal reproduction. Our tunnel-digging Prairie dog, for example, is not being altruistic by Hamil- ton's definition because she will ultimately benefit from the tunnels she builds via positive effects on her town's foraging. Hamilton's definition has been called strong altruism in order to emphasize its stringency and differentiate it from a definition that is often favored by the group selectionist (Wilson 1990). The group selection definition of altruism includes any behavior that lowers the actor's competitive ability within the group but benefits the group as a whole. Hamilton's strong altruism is included here as a subset but so are examples such as the Prairie dog where within-group fitness decreases, but overall reproduction increases (weak altruism). Returning then to the question of whether altruism can be favored without kin selectionwhere kin selection is natural selection effected by relatedness among individuals in a group - the answer for strong altruism is no (Foster et al. 2006a,b). Strong altruism relies on relatedness among individuals because this is the only way that an individual can gain an inclusive fitness benefit that compensates for a guaranteed reduction in lifetime reproduction.

There has been a recent claim to the contrary (Fletcher and Doebeli 2009). This appeals to an imagined scenario where different loci encode strong altruism in different individuals. Even though individuals are genetically different, altruism can invade if altruists are for some reason kept together and away from defectors. The problem with this argument is that this outcome will be short lived. Any modifier that causes carriers of one of the altruistic loci to no longer be altruistic would outcompete other altruist loci within any group. One might counter this with the added assumption that that new defector mutants are also somehow excluded from altruist groups. However, this then implies a causal link between "altruism" and personal reproductive benefit, via group membership; i.e., it is not altruism but mutualism (Fig. 2). The same argument can be made for cases of greenbeard cooperation, i.e., it is either unstable or a case of mutualism (see Smukalla et al. 2008). In contrast, weak altruism can evolve stably among unrelated individuals when helping others also provides personal reproductive benefits (Wilson 1990). Finally, "reciprocal altruism" (Trivers 1971) is something different again, where there is a delayed direct fitness benefit that comes back to the actor from the recipient of a social action. The average fitness effect of reciprocal altruism is to always increase the actor's personal fitness. These different meanings of altruism are further discussed in Foster (2008).

\section{Group Selection}

It will come as no surprise that there is also confusion and debate over the meaning of group selection. Leaving aside how to actually define a group, multiple meanings of group selection exist (for review, see Okasha 2006; Gardner and Foster 2008) and this might be taken as evidence for the insufficiency of group selection theory (West et al. 2008). The most common definition of group selection comes from the multilevel selection form of the Price equation (Price 1970, 1972), which partitions the evolutionary response to natural selection into change within groups and among groups. From this, the definition of group selection 
is simply the differential productivity and survival of groups. This definition, however, ascribes group selection to completely asocial individuals that just happen to be near one another. Consider some hypothetical snails that live on a patchy resource but do not affect one another. If large snails survive better and some patches contain more large snails, those groups will have a higher productivity and group selection is detected in the Price equation. For those interested in the effects of group selection because of social evolution, this can seem unsatisfactory (Okasha 2006).

An alternative way of assessing group selection, as developed by Heisler and Damuth, makes use of a statistical technique from the social sciences called contextual analysis (Heisler and Damuth 1987; Goodnight et al. 1992; Okasha 2006). Again, this partitions natural selection into individual and group effects, but, importantly, it only pulls out the group effects on fitness that cannot be explained by individual effects. This means that group selection is only detected when there are effects of group identity on fitness that remain once one has controlled for individual effects on fitness (one calculates the partial regression between group phenotype or genotype and individual fitness).

Further testament to the equivalence of kin and group selection comes from the fact that contextual analysis is nearly identical to the modern kin selection models that are based on neighbor-modulated fitness (see introduction, boxed text), although the two were largely independently derived within evolutionary biology. Personally, I find contextual analysis an intuitive way to define group selection, although the Price partition is more commonly used (Gardner et al. 2006; Gardner and Grafen 2009). An objection raised to contextual analysis is that it detects group selection when all groups have identical productivity but the ranking of individuals within groups matters for fitness (soft selection). There is group selection without groups actually differing in their fitness (Heisler and Damuth 1987; Goodnight et al. 1992; Okasha 2006). In the end, group selectionists must choose whether they are most interested in the differential productivities of a subdivided population (Price) or the evolution of social traits (contextual) and then go from there (Okasha 2006). But again, the existence of this choice does not undermine the enterprise.

\section{Group Adaptation}

By now, I hope that the reader is (or remains) convinced that the evolution of a strongly altruistic behavior-like a self-sacrificing insect worker - can be phrased in terms of kin or group selection. This is true even though kin selection is the more natural fitness partition for the case of strong altruism (Foster et al. 2006a). The kin selectionist can view the dying worker in terms of a beneficial trade-off between personally passing on the allele for conditional self-sacrifice versus helping her more fecund relatives to pass on the allele. The group selectionist can see that the sacrifice will have a negative fitness effect on the individuals that express it but a positive fitness effect on the groups that carry it. The two perspectives can be also combined as was done by H.G. Wells (Wells et al. 1929) above. Should self-sacrifice also be viewed as a group adaptation? To attempt an answer, one must first distinguish between selection and adaptation (Gardner and Grafen 2009). Natural selection is the change in allele frequencies that results from differences in survival and reproduction, where critically, these differences are caused by an individual, or group, carrying one allele (or set of alleles) rather than another. Adaptation is more difficult to define but is typically viewed as the process of optimizing a phenotype for an organism's environment (Fisher 1930), for example, the production of a more efficient wing for flight. What then distinguishes group adaptation from individual adaptation? This remains an open point of discussion in sociobiology, and legitimately so (Gardner 2009; Gardner and Grafen 2009).

If adaptation is the process of optimizing a phenotype for its environment and natural selection is the process that drives this optimization, we can reach a definition of group adaptation from the contextual analysis definition of group selection (see previous section). Group adaptation is the process of optimizing cooperative phenotypes that depends on group context. More specifically, it is the optimizing process that is dependent on the component of natural selection that contextual analysis ascribes to the group. Put this way, the products of group adaptation are those shaped by the partial effect of group phenotype on individual fitness (controlling for the effects of individual phenotype). In modern systems, this should translate roughly into the cooperative components of phenotypes that only provide a fitness benefit in the group context. These very general conditions will find evidence for group adaptation in many situations, including workers that sacrifice themselves to defend their colony, our tunnel-digging Prairie dog, and any degree of self-restraint in resource use that promotes group survival; all phenotypes that can only be explained by group-level function.

Gardner and Grafen (2009) offer a more stringent definition of group adaptation in their discussion of the superorganism: the associated idea that individuals in highly organized societies are comparable to cells in an organism (Wheeler 1911). For Gardner and Grafen, true group adaptation implies that the group is acting as the agent of natural selection, and they are only able to find that the latter is the case when societies have negligible reproductive conflict among their members. The argument is that expressed conflict means that individual-level selection is compromising group function and, accordingly, adaptation is not operating to generate function at the level of the group. Instead, Gardner and Grafen suggest that most phenotypes are best viewed as the product of individual adaptation, which, in turn, is the result of inclusive fitness maximization. Although this argument carries merit, and rescues the idea of the individual as an evolutionary agent (Gardner and Foster 2008), it excludes many derived social phenotypes from group adaptation. Stingless bees, for example, suffer horrific conflicts over queen production whereby hundreds of larvae will try to develop into new queens only to be immediately executed by the workers (Wenseleers et al. 2003; Wenseleers and Ratnieks 2004). However, these same workers will aggressively (albeit by biting rather than stinging) defend the nest in a manner intuitively consistent with group adaptation. Another potential objection to 
Gardner and Grafen's (2009) argument is that true multicellular organisms are not free from conflict either (Wilson and Wilson 2008) but suffer from cancers and selfish genetic elements that may have a nonnegligible effect on organismal adaptation (Hurst et al. 1996; Burt and Trivers 2006; Merlo et al. 2006).

Rather than taking conflict to indicate a complete lack of group adaptation, therefore, one can instead ask how well adapted is a particular social trait or group? Put another way, the effectiveness of group adaptation can be assessed by asking how similar an extant group is to one that completely lacks conflict, such as a clonal group (Foster 2004; Ratnieks et al. 2006). Such thought experiments do not suppose that perfectly cooperative groups are truly optimal, just that their adaptations are the product of the best optimization process that is available, given realistic constraints of both biology and the evolutionary process. Even so, such assessments are typically only approximate as the exact form of a conflict-free group is unknown in most species. Moreover, even clonal groups might not be always well adapted because natural selection can disfavor clonality itself to combat disease (Hamilton 1987; Sherman et al. 1988) or improve social organization (Brown and SchmidHempel 2003). However, this objection may not be watertight given that natural selection on clonal groups is known to produce genetic diversity while maintaining clonality where it matters, as found in one's own immune system.

A related approach to group adaptedness is that of Queller and Strassmann (2009) who offer a two-dimensional index of "organismality," upon which social groups - of one or more species - can be placed. Their first axis "conflict" defines the group by the degree of observed conflict, which is roughly analogous to my comparing a real group to a perfectly cooperative one. Their second axis "cooperation" adds to this by asking how much do individuals appear to help one other? An illustrative example here are nongalling aphids that might exist in clonal groupswith little conflict - but do not really help one another, perhaps because there is little to be gained (Queller and Strassmann 2009). By these measures, organismality is awarded to groups with low conflict and cooperation that pays great fitness dividends. The argument that a multiple species group can be viewed as an organism (Queller and Strassmann 2009) also invites the possibility of community-level adaptation. From the perspective of contextual analysis, community-level adaptation would be when positive fitness effects on other species provide feedback benefits to a focal species that shape its phenotype, where again direct fitness effects of phenotype on the focal individual (or group) have been removed. To conclude, one can argue that the process of group adaptation is as common in social groups as is contextual group selection, but it remains an open question how adapted are different social species relative to the ideal of a conflict-free group.

\section{THE DATA}

[the problem of the superorganism] must be solved by field and laboratory research, not by mathematical modeling. E.O. Wilson (pers. comm.)
In their recent book, Holldobler and Wilson also revisit the idea that social adaptations can be so derived that a group of animals can be considered a superorganism (Wheeler 1911). As discussed in the last section, this question is closely linked to the problem of group adaptation and, like Hamilton's papers (Hamilton 1964), recent theory has emphasized the importance of genetic relatedness in the emergence of the superorganism (Reeve and Holldobler 2007; Gardner and Grafen 2009). In criticizing theoretical sociobiology, Wilson argues not only that kinship theory has made no useful predictions but also that understanding the superorganism - and, by inference, social evolution in general - is an empirical rather than theoretical question (Wilson and Holldobler 2005; E.O. Wilson, pers. comm.). Although I clearly do not endorse these views, it is vital to consider the data. Does empiricism, like theory, support the mutual importance of kin and group selection? The answer again is a resounding yes.

\section{Kin Selection}

Hamilton's kin selection centers on the idea that fitness costs and benefits, weighted by genetic relatedness, are critical for social evolution. As such, proving the importance of relatedness for cooperation and altruism (see Fig. 2) does not invalidate the role of other factors that affect costs and benefits, including ecology and preadaptations. These different explanations are not in opposition, as Wilson attests, but rather all parts of one big puzzle. This point of logic is mirrored in the easily neglected distinction between necessary and sufficient that is used in genetics. An important gene can be strictly necessary for a phenotype, such as obesity, without being sufficient to produce the whole phenotype on its own. Similarly, it can be that relatedness is strictly necessary for strong altruism to evolve but that it is not sufficient without other preadaptations and ecological factors (Korb and Heinze 2008). Although I argue below that relatedness is extremely important for social evolution, therefore, I am not arguing that it is the only factor of importance. And at the risk of repetition, nor am I arguing that kin selection theory is only about relatedness. It is not: Fitness costs and benefits are critically important in any calculation of fitness effects (Fig. 2). The theory remains valid when one moves from nonzero relatedness among actor and recipient to zero relatedness (although the calculations do get rather easier).

The Social Insects. The evolutionary origin and maintenance of the spectacular worker castes in social insects have long been a centerpiece for discussion of social behavior and altruism. More specifically, these discussions center on the "eusocial" insects, which are those that display a fixed division between work and reproduction among individuals (Boomsma 2007, 2009). The key eusocial groups are found in the hymenoptera (bees, ants, and wasps) and the distantly related termites, but several other arthropods get close, including thrips, beetles, aphids, and even shrimp. As emphasized above, explaining the patchy distribution of eusociality will likely require consideration of multiple preadaptations, which 
include the potential to build a well-defended group (nest building and stings; Wilson 1971) and the possibility to guarantee that the individuals one helps will survive if one does not (Queller 1989; Gadagkar 1990). However, the potential role of relatedness in eusociality is also immediately apparent in the finding that the societies of these species are nearly always formed by immediate family. There are exceptions, including the unicolonial ants that form massive networks of interconnected nests with so many queens that the workers can end up barely related to one another. However, these are thought to be evolutionary dead ends, and, anyway, it is clear that when the worker castes originally evolved, they were living as families (Helanterä et al. 2009).

More pause for thought might come from "primitively" eusocial hymenoptera: Species that lack physically distinct queen and worker castes and whose nests can be founded by multiple unrelated foundresses (Bernasconi and Strassmann 1999). As these foundressses begin to produce daughter workers, a family group is created, but there are still many unrelated individuals in the nest. This suggests that worker behavior can evolve in the presence of relatively low relatedness, but importantly the "workers" in this case are individuals - like the queen - who have the potential for independent reproduction. That is, worker behavior in these species likely evolves through a mixture of kin-selected benefits and delayed reproductive benefits (Boomsma 2009). Nevertheless, if this were to be the route by which the truly eusocial species - such as the honeybee-were to evolve, one could argue that only low relatedness was necessary for the origin of the derived worker castes. This would not invalidate kin selection thinking but would emphasize the importance of ecological factors relative to family life. However, arguing from anecdote is not sufficient. What is needed are phylogenetic analyses and here the data are clear: The multiple ancestors of the eusocial hymenoptera were very likely all species with a single queen that mated to a single male (Boomsma and Ratnieks 1996; Foster and Ratnieks 2001; Boomsma 2007, 2009; Hughes et al. 2008). What is striking about this is that single mating appears to be an unusual state of affairs for most animals, where promiscuity is common. This led Boomsma (2007, 2009) to argue that monogamy - and the high family relatedness that results - may be a strict prerequisite for the origin of the highly eusocial insects. More data are needed to know whether strict monogamy is always absolutely required, but the evidence that monogamy favors eusociality in hymenoptera is already compelling. Eusocial species arose from family groups, and, for the cases analyzed, these ancestral societies were founded by a single mother mated to a single male.

One can also ask of the role of relatedness in the maintenance of eusociality. Many derived eusocial species such as honeybees, yellow jacket wasps, and leaf-cutter ants have secondarily evolved multiple mated queens, which causes low relatedness among the workers. Why then do these species not suffer from severe internal conflicts among their workers over reproduction? For the long answer to this question, one can turn to dedicated reviews (Bourke and Franks 1995; Ratnieks et al. 2006), but, briefly here, multiple mating actually helps to resolve conflicts once derived eusociality is in place. Moreover, the way that this works provides further evidence for the importance of relatedness in social evolution. In the derived eusocial hymenoptera, workers cannot mate but can typically produce eggs. These eggs develop into males because of the unusual haplodiploid genetics of the hymenoptera, in which females are diploid and males are haploid. Workers can therefore compete with the queen over male production, and what stops this from becoming a reproductive melee is that workers tend to eat each others' eggs. The workers police one other.

Worker policing is predicted to be prevalent in species where the queen mates many times because in haplodiploids, this reduces relatedness among the workers but not between the workers and their brothers (the queen's sons). With queen multiple mating, therefore, the workers are expected to favor the queen's sons over each others' (Ratnieks 1988). The outcome is that once distinct queen and worker castes have evolved, reduced worker relatedness is predicted to promote cooperation by promoting policing. In support of this, there is a negative correlation between worker relatedness and the effectiveness of policing and a positive correlation between relatedness and the proportion of workers that attempt to lay (Fig. 3a) (Wenseleers and Ratnieks 2006a,b). Even better, in colonies where the queen has died, the correlation between relatedness and worker reproduction reverses (Fig. 3b) (Wenseleers and Ratnieks 2006b), exactly as predicted by the basic theory (Hamilton 1964; Wenseleers et al. 2004a). Without the queen, the workers now have no reason to police for the queen's benefit, and relatedness only functions to limit the severity of competition among the workers. The outcome in the highly multiply mated honeybee is that colonies with a queen see almost no conflict among the workers, but queenless colonies are highly chaotic. In contrast, the queen's presence has little effect on worker rebellion in wasp species where the queen mates only once (Fig. 3).

Evidence for the role of genetic relatedness is also seen in other social insects, including termites, where a single king and a single queen head the colonies in a monogamous relationship, and aphids, which are clonal. Like monogamy, clonality makes raising parents' offspring just as genetically beneficial as raising one's own offspring (Boomsma 2007). Furthermore, in both termites and aphids, there is evidence of kin effects when members of different colonies meet. Aphids are less likely to altruistically defend the colony when they are in the nest of a foreign clone (Abbot et al. 2001), and, when short on food, termites will preferentially direct aid to their relatives within colonies where two different families have fused (Korb 2006). A recent paper communicated by E.O. Wilson to Proceedings of the National Academy of Sciences claimed that eusocial evolution in termites can occur "even when indirect fitness benefits are low or nonexistent" (Johns et al. 2009). The evidence for this was primarily the observation that colony fusion can temporarily reduce relatedness within colonies and lead to a system of serial monogamy, rather than lifetime monogamy. However, this example concerns one of the lower 
A Policing + kin selection: Colonies with a queen

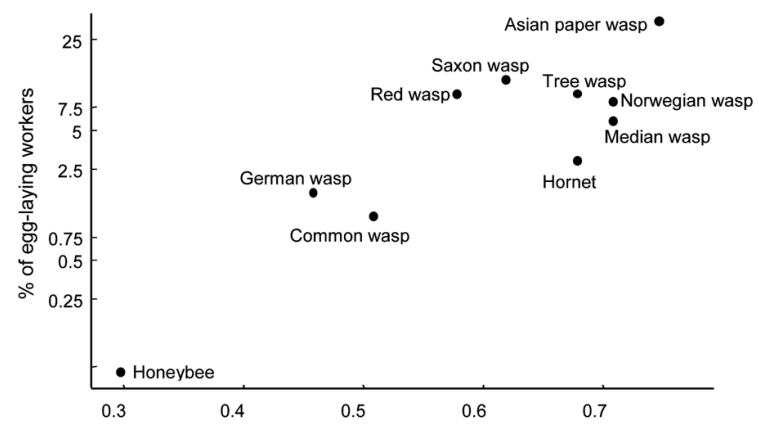

B Kin selection: Colonies without a queen

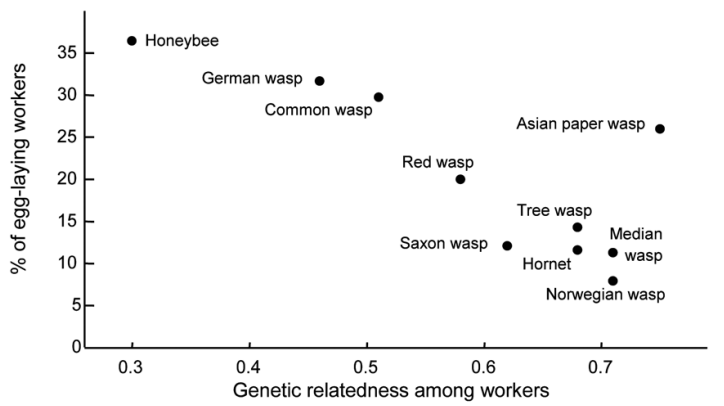

Figure 3. Worker altruism in derived eusocial insects is driven by a combination of kin selection and worker policing. $(A)$ Altruistic self-restraint due to policing. In colonies where the mother queen is alive, the workers can raise either the queen's or other workers' eggs. In species where relatedness among workers is high, they tend to raise the workers' eggs because they are highly related to them, but in species where relatedness among workers is low, such as the honeybee, workers remove one anothers' eggs. This reduces the benefits to worker reproduction which, alongside indirect fitness benefits, promotes reproductive self-restraint. (B) Altruistic self-restraint due to inclusive fitness effects. If the queen dies, the workers compete to lay eggs. However, when relatedness is high, many show altruistic selfrestraint and do not attempt to reproduce. (Reprinted, with permission, from Wenseleer and Ratnieks 2006b [CNature Publishing Group].)

termites, which are now generally considered not to have passed the irreversible threshold toward permanent eusociality as helpers retain ample options for direct reproduction later in life (Korb 2007; Boomsma 2009). So, worker relatedness may occasionally be low in lower termiteswhich are essentially cooperative breeders (Korb 2007) and also in isolated branches of the higher termites, as rare secondary developments after eusociality had become irreversibly established. However, nothing in the Johns et al. (2009) study would indicate that either cooperative breeding in the lower termites or eusocial breeding in the higher termites is not associated with full-sibling relatedness as a norm.

Other societies. Although I have focused on the eusocial insects, considerable evidence also exists for the importance of relatedness in other social species, including impressive meta-analyses on social vertebrates. The social vertebrates are bird and mammal species, including the charismatic meerkat, that live together in tight groups and help one another to raise offspring. Here, species with a higher fitness benefit to helping behaviors tend to discriminate more among relatives and nonrelatives as predicted by kin selection theory (Fig. 4a) (Griffin and West 2003). Furthermore, in those species where kin discrimination is weak, there tends to be higher average relatedness in social groups, suggesting that kin-selected benefits to helping can still occur in species that do not show kin discrimination (Fig. 4b) (Cornwallis et al. 2009).

The importance of genetic relatedness is also supported by a recent surge of studies on microorganisms (West et al. 2006; Foster 2010; Nadell et al. 2009). For example, mixing unrelated strains promotes the evolution of rapid wasteful growth in bacterial viruses (Kerr et al. 2006). Reducing relatedness among cells also promotes the success of cheater mutants that do not contribute to the common good in a host of systems, including enzyme secretion in yeast (Greig and Travisano 2004), iron scavenging and quorum sensing in the bacteria Pseudomonas aeruginosa (Griffin et al. 2004; Diggle et al. 2007), and in the development of the bacterium Myxococcus xanthus (Velicer et al. 2000) and the slime mold Dictyostelium discoideum, where a myriad of cheater mutants have now been found (Ennis et al. 2000; Gilbert et al. 2007; Santorelli et al. 2008). Considerable evidence also exists for kin discrimination systems, including bacteria that spitefully secrete a toxin to kill unrelated strains (Gardner and West 2004; Gardner et al. 2004), self/non-self-recognition in slime molds (Mehdiabadi et al. 2006) and single-gene green beard recognition in both slime molds (Queller et al. 2003) and yeast (Smukalla et al. 2008). Finally, there is evidence that microbes can change their social strategy in the presence of relatives versus nonrelatives. For example, it was recently shown that the allocation to spores (germ) versus stalk (soma) in slime molds will increase in the presence of unrelated strains as predicted by kin selection theory (Buttery et al. 2009).

To close the case on kin selection data, "kinship theory" has made exquisitely supported predictions in many other systems. An example is the annual plant that increases allocation to roots when its roots meet a nonrelative (Dudley and File 2007). Another comes from the wasp Nasonia vitripennis. Female wasps lay a very femalebiased sex ratio when they parasitize fly larvae, which fits well with the predicted effects of relatedness on sex ratios. This is because sons and daughters mate in the host, and it is most efficient to have a few sons and limit competition among them (Hamilton 1967). What is even more impressive is that when a second female lays in the same host, she is able to detect the first brood and shift her sex ratio to produce many more males to compete with the unrelated males already in the host (Werren 1980). The result is a tight association between relatedness among wasps within a host and the sex ratio (Fig. 5). One can even apply kin selection thinking to the evolution of sperm, where a host of surprising social behaviors occur including sperm that hook onto one other and swim as a cooperative group (Pizzari and Foster 2008; Fisher and Hoekstra 2010). 
A

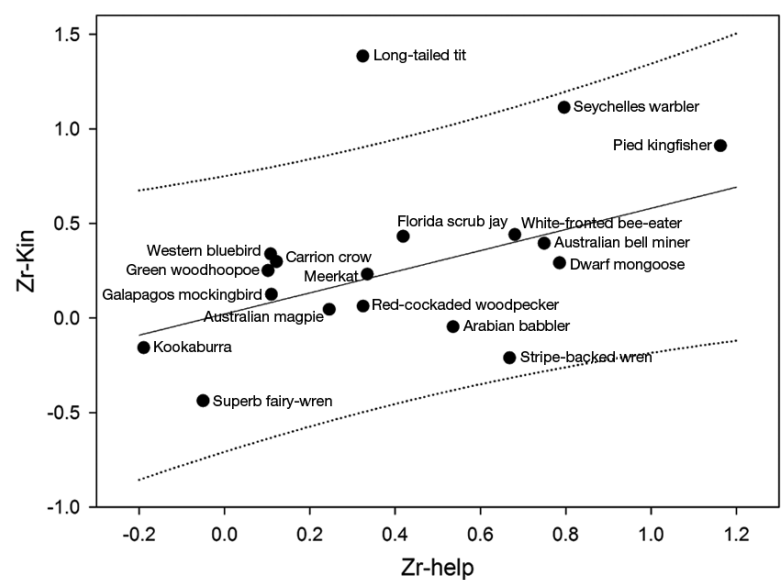

B

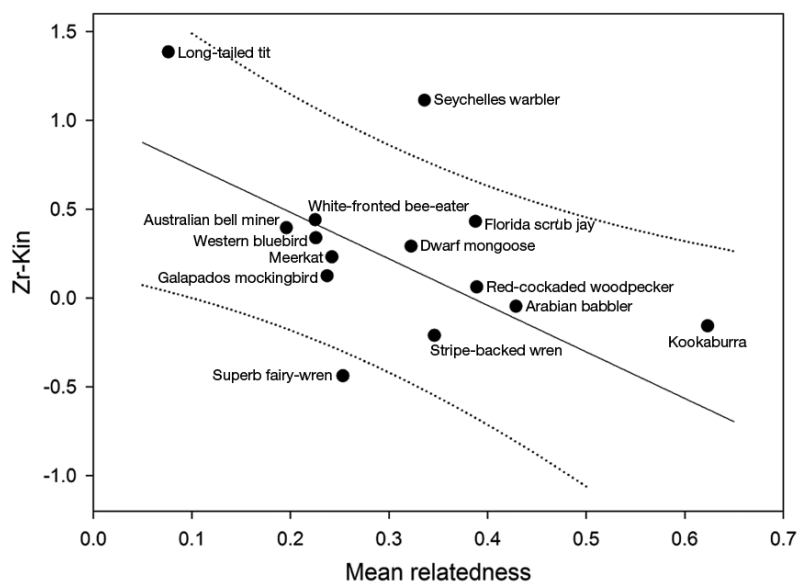

Figure 4. Helping behaviors in social vertebrates. $(A)$ Species with a higher fitness benefit to helping behaviors tend to discriminate more among relatives and nonrelatives as predicted by kin selection theory (Griffin and West 2003). "Zr-Kin" and "Zr-help" are statistical measures of the degree of kin discrimination and the fitness benefits of helping behavior, respectively. $(B)$ In species where kin discrimination is weak, there tends to be higher average relatedness in social groups, suggesting that kin-selected benefits to helping can still occur in species that do not show kin discrimination. (Reprinted, with permission, from Cornwallis et al. 2009 [CWileyBlackwell].)

\section{Group Selection}

Group selection has received less empirical attention than kin selection (West et al. 2007, 2008; Wilson 2008a), but due to the equivalency of the theories, support for one can typically be taken as support for the other. Certainly, the wealth of data showing the role of relatedness, costs, and benefits in the evolution of altruism is completely consistent with the idea that individuals are sometimes selected to favor the welfare of their group over personal reproduction.

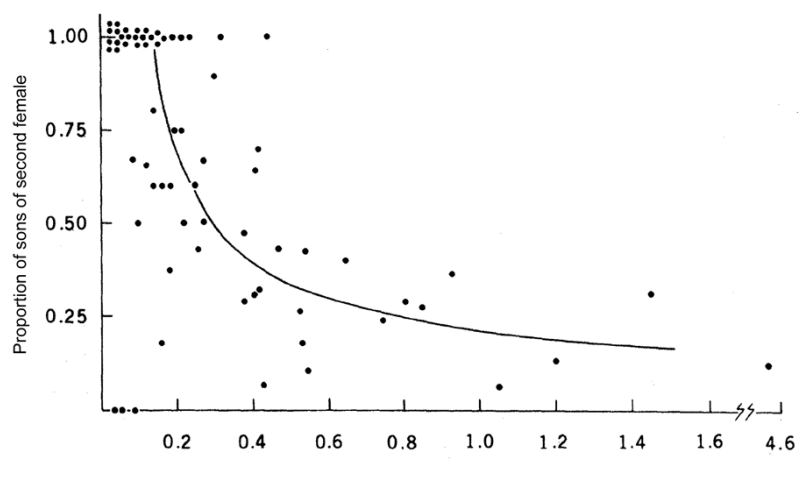

Ratio of second female's offspring to first female's offspring

Figure 5. The sex ratio laid by the second female to parasitize a host in the wasp Nasonia vitripennis. The line shows the predicted optimal ratio of a second female as a function of the relative numbers of the two females' offspring, which determines average relatedness among the wasps in the host (Hamilton 1967). The plotted points show the actual empirical sex ratios. The wasps also respond as qualitatively predicted to factors such as synchrony in egg-laying and the degree of parasitism in a patch at the time of laying (Shuker et al. 2005, 2006). (Reprinted, with permission, from Werren 1980 [CAAAS].)
There are also explicit tests of group selection logic (Goodnight and Stevens 1997; Wilson and Wilson 2007). These take two key forms: experimental evolution and contextual analysis. Like the classic work on the fruit fly, experimental evolution studies on group selection take organisms through multiple generations and select on certain traits. The key difference to typical studies is that one selects on the group mean of phenotypes, rather than the individuals that best display a trait. Such studies on flour beetles have shown responses to group selection on several traits including body size, group size, and dispersal (Wade 1976, 1977; Craig 1982). A key conclusion is that group selection can work, even when group and individual selection are pitted against each other. A similar study has been performed on leaf area in the plant Arabidopsis thaliana (Goodnight 1985), and group selection logic found a commercial application in chickens, where selecting on groups for survival and egg-laying improved both the productivity and welfare of the birds (Craig and Muir 1996; Muir 1996). A nice aspect of the chicken work is that it makes clear that both group and family selection are central to the results: "The hypothesis was tested that selection on the basis of family means for increased survival and henhoused egg production, when sisters with intact beaks were kept together in multiple-bird cages, would cause adaptive changes in behavior... . The evidence supported the hypothesis." (Craig and Muir 1996). Similarly, the abovementioned study of Kerr et al. (2006) on the evolution of virulence in bacteriophage has subsequently been taken as evidence for both group (Wilson and Wilson 2007) and kin (Foster 2009) selection thinking.

Experimental group selection has also been applied to communities containing multiple species. The first such study selected on flour beetle population size and dispersal but this time with two species present. Group selection 
on one species was again effective in changing the targeted traits in that species (Goodnight 1990a,b). Moreover, it was also found that selection on one species can drive evolutionary changes in the other, and these changes were only observable when both species were raised together. More recently, community-level selection on an even broader scale was performed on microbial communities in soil and water (Swenson et al. 2000) by selecting either on the plant growing in the soil or on the $\mathrm{pH}$ of the water. Although the changes in the microbial communities were unknown, there was a clear evolutionary response in community phenotype. Is such community-level selection outside of the remit of kin selection logic? Even here the answer is no. For selection to effectively act on the community, there is still the need for genetic differences among groups at the level of each species, i.e., genetic relatedness. However, one does need to extend the standard kin selection models to allow for any feedback effects that come from helping or harming other species in the community (Foster and Wenseleers 2006).

The second major approach to studying group selection comes from the application of contextual analysis (Heisler and Damuth 1987; Goodnight et al. 1992; Bijma et al. 2007). Not only is contextual analysis a conceptual tool by which one can define group selection (above), it is also a statistical technique that can be used to dissect the effects of individual and group selection in real systems. For example, Goodnight et al. (1992) showed that one could detect components of group, soft, and hard selection for leaf area in a data set on A. thaliana. More recently, antagonistic selection across the individual and group level was shown in another $A$. thaliana data set (Weinig et al. 2007). The authors here asked how individual fruit production correlated with individual and group phenotypes for groups of plants in both the laboratory and the field. Individual selection appears to favor larger plants that can compete well against other individuals, whereas group selection favors smaller plants, which presumably limit competition that is wasteful at the group level. In sum, there is ample empirical evidence that group selection can operate in real biological systems, but none of these data counter the studies motivated more by kin selection thinking. Again, group selection is only effective when there is relatedness between an actor and the group, be it relatedness of the actor to themselves, relatedness of the actor to other group members, or both.

\section{CONCLUSION}

...group-related adaptations do not, in fact, exist. A group in this discussion should be understood to mean something other than a family and to be composed of individuals that need not be closely related.

Williams (1966)

Williams' provocative attack on the idea of group selection and group adaptation has been a centerpiece in discussions of group selection for 40 years. Initially, it was widely accepted as the correct viewpoint and a necessary antidote to the naïve group selection logic of
Wynne-Edwards and other investigators (Trivers 1985; Gardner and Foster 2008). More recently, Williams' view has been held up as a severe overreaction and one that excludes a whole host of important examples of group adaptation (Wilson and Wilson 2007, 2008). Williams' early view may retain some merit, however, in that he was questioning not the general importance of group selection and adaptation, but specifically its importance outside of the family group. Theoretically, there is no absolute barrier to group selection or even group adaptation in nonkin groups. Perfect relatedness is not needed for group adaptation, and, anyway, relatedness can occur by means other than strict kinship. However, the theory also suggests that group adaptation will be most prevalent when relatedness is high (Hamilton 1964; Foster 2004; Gardner and Grafen 2009), and this seems to be typically achieved by family life. The best examples of group adaptation, ranging from the social insects (Boomsma and Ratnieks 1996; Foster and Ratnieks 2001; Boomsma 2007, 2009; Hughes et al. 2008) to the social amoebae (Gilbert et al. 2007), appear to be tightly associated with kinship. It is further telling that papers that are explicitly aimed at promoting group selection over kin selection are full of examples involving family groups (Wilson and Wilson 2008).

Although Williams probably overstated his case, therefore, the idea that family is at the root of the most striking group adaptations may yet prove to be correct. One must also admit the possibility of publication bias, given the relative emphasis on kin selection over group selection in recent years (Wilson and Wilson 2007). This bias may decline: A recent study on water striders suggests that group selection can operate through nongenealogical relatedness created through differential dispersal of genotypes (Eldakar et al. 2009). Furthermore, I have focused here on the idea of group adaptation as a within-species phenomenon, but the strongest case for adaptations that transcend the family will likely come from the community level: tight mutualisms such as the mitochondria that live in our cells (Queller and Strassmann 2009). A systematic analysis of the importance of adaptation at the level of family groups, nonkin groups, and multiplespecies groups remains an open challenge for sociobiology, one that will require careful theory, semantics, and empiricism. Accordingly, the study of selective effects at the highest levels, both community (Williams and Lenton 2008) and species (Rankin et al. 2007a,b), is an emerging area of interest.

Another exciting avenue for sociobiology is the study of mechanism. Indeed, it is only in closing that I come to the topic that is at the heart of the 74th Cold Spring Harbor Symposium on Quantitative Biology and my own research: the molecular mechanisms underlying evolutionary change (Foster et al. 2007; Nadell et al. 2009). Like many areas of evolutionary biology, sociobiology has seen recent growth in the study of molecular mechanisms (Robinson 1999; Robinson et al. 2005; Smith et al. 2008). Not only is this important for unifying molecular biology and sociobiology, but it is also a source of novel evolutionary insight. That said, in making important links between proximate mechanistic explanations and ultimate evolutionary expla- 
nations, one must not conflate one with the other (West et al. 2007). Consider the following close of a Science paper on the evolution of worker behavior in wasps: "The bivoltine ground plan hypothesis of caste evolution in Polistes inaugurates a changed perspective on the evolution and maintenance of sociality in insects. It shifts emphasis away from altruism, away from costs and benefits, and away from conflict and cooperation. It states that evolutionary trajectories of sociality are best understood as having been shaped by regulatory circuits present in solitary ancestral forms. It calls for a mechanistic approach to caste evolution..." (Hunt and Amdam 2005). If this is intended as an argument for incorporating mechanism into sociobiology, this is a welcome - if strongly phrased - appeal. However, the strongest evolutionary implication for the study is that having two different life cycles per year (bivoltinism) preadapted wasps to evolve queen and worker behavior. Again, this particular preadaptation may or may not prove necessary worker behavior, but this does not make it a sufficient condition for the evolution of altruism. There is no challenge here to the logical necessity of relatedness for strongly altruistic workers.

Caveats in hand, recent studies of mechanism have provided evolutionary insight. This includes suggestions that social adaptations may often arise through relatively modest changes to solitary phenotypes (Hunt et al. 2007; Smith et al. 2008; Korb et al. 2009), that pleiotropy may constrain the evolution of cheating (Foster et al. 2004; Smith et al. 2009), that social systems can be rescued from conflict-driven collapse by a single mutation (Fiegna et al. 2006), and that single genes can act as green beards (Queller et al. 2003; Smukalla et al. 2008). Some of the growth in mechanistic study goes hand in hand with another rapidly developing area: the sociobiology of communication (d'Ettorre and Hughes 2008). For social insects, this involves dissecting the myriad of chemical signals and cues that allow them to coordinate and manipulate one another in a colony (Heinze and d'Ettorre 2009). Finally, the field of collective behavior is a fascinating blend of evolutionary and mechanistic studies that seeks to understand the way that social groups are able to organize themselves (Couzin 2007; Couzin et al. 2002; Simpson et al. 2006; Sumpter 2006). A challenge for the future is to combine the study of self-organization and emergence with that of cooperation and conflict (Xavier et al. 2009), something that again surely can be done with both sets of theories remaining intact. As we move forward then with the study of mechanism, group selection, and altruism, I hope it will be increasingly with an air of pluralistic tolerance to the ideas and frameworks of one another (Foster 2006). Debate and dissent are a productive and necessary part of science, but before we engage them, we might be a little more careful to check that there really is something to discuss. At its core, sociobiology stands solid and is there to be built upon.

\section{ACKNOWLEDGMENTS}

This chapter has been greatly influenced and helped by discussions with many people including Koos Boomsma,
Charlie Cornwallis, Thomas Dixon, Andy Gardner, Ashleigh Griffin, Jim Hunt, Laurent Keller, Sarah Knowles, Hanna Kokko, Laurent Lehmann, Samir Okasha, Dave Queller, Daniel Rankin, Francis Ratnieks, James Schwartz, Joan Strassmann, Tom Wenseleers, Stuart West, D.S. Wilson, and Edward O. Wilson.

\section{REFERENCES}

Abbot P, Withgott JH, Moran NA. 2001. Genetic conflict and conditional altruism in social aphid colonies. Proc Natl Acad Sci 98: $12068-12071$.

Alcock J. 2005. Animal behavior: An evolutionary approach, 8th ed. Sinauer, Sunderland, MA.

Axelrod R, Hamilton WD. 1981. The evolution of cooperation. Science 211: 1390-1396.

Bernasconi G, Strassmann JE. 1999. Cooperation among unrelated individuals: The ant foundress case. Trends Ecol Evol 14: 477-482.

Bijma P, Muir WM, Van Arendonk JAM. 2007. Multilevel selection. 1. Quantitative genetics of inheritance and response to selection. Genetics 175: 277-288.

Boomsma JJ. 2007. Kin selection versus sexual selection: Why the ends do not meet. Curr Biol 17: R673-R683.

Boomsma JJ. 2009. Lifetime monogamy and the evolution of eusociality. Philos Trans R Soc Lond B Biol Sci 364: 31913207.

Boomsma JJ, Ratnieks FL. 1996. Paternity in eusocial hymenoptera. Philos Trans R Soc Lond B Biol Sci 351: 947-975.

Bourke AFG, Franks NR. 1995. Social evolution in ants. Princeton University Press, Princeton, NJ.

Brown MJF, Schmid-Hempel P. 2003. The evolution of female multiple mating in social hymenoptera. Evolution 57: 20672081.

Burt A, Trivers RL. 2006. Genes in conflict: The biology of selfish genetic elements. Harvard University Press, Cambridge, MA.

Buttery NJ, Rozen DE, Wolf JB, Thompson CRL. 2009. Quantification of social behavior in D. discoideum reveals complex fixed and facultative strategies. Curr Biol 19: 13731377.

Christiansen FB. 1991. On conditions for evolutionary stability for a continuously varying character. Am Nat 138: 37-50.

Cornwallis C, West SA, Griffin AS. 2009. Routes to indirect fitness in cooperatively breeding vertebrates: Kin discrimination and limited dispersal. J Evol Biol 22: 2445-2457.

Couzin I. 2007. Collective minds. Nature 445: 715.

Couzin ID, Krause J, James R, Ruxton GD, Franks NR. 2002. Collective memory and spatial sorting in animal groups. $J$ Theor Biol 218: 1-11.

Craig DM. 1982. Group selection versus individual selection: An experimental analysis. Evolution 36: 271-282.

Craig JV, Muir WM. 1996. Group selection for adaptation to multiple-hen cages: Behavioral responses. Poult Sci 75: 11451155.

Darwin CR. 1859. On the origin of species by means of natural selection, 1st ed. Murray, London.

Dawkins R. 1976. The selfish gene. Oxford University Press, Oxford.

d'Ettorre P, Hughes DP. 2008. Sociobiology of communication: An interdisciplinary perspective. Oxford University Press, New York.

Diggle SP, Griffin AS, Campbell GS, West SA. 2007. Cooperation and conflict in quorum-sensing bacterial populations. Nature 450: 411-414.

Dixon T. 2008. The invention of altruism: Making moral meanings in Victorian Britain. British Academy/Oxford University Press, Oxford.

Doebeli M, Hauert C. 2005. Models of cooperation based on the Prisoner's Dilemma and the Snowdrift game. Ecol Lett 8: 748766.

Doebeli M, Hauert C, Killingback T. 2004. The evolutionary ori- 
gin of cooperators and defectors. Science 306: 859-862.

Dudley SA, File AL. 2007. Kin recognition in an annual plant. Biol Lett 3: 435-438.

Dugatkin LA, Reeve HK. 1994. Behavioral ecology and levels of selection-Dissolving the group selection controversy. $A d v$ Study Behav 23: 101-133.

Eldakar OT, Dlugos MJ, Pepper JW, Wilson DS. 2009. Population structure mediates sexual conflict in water striders. Science 326: 816.

Ennis HL, Dao DN, Pukatzki SU, Kessin RH. 2000. Dictyostelium amoebae lacking an F-box protein form spores rather than stalk in chimeras with wild type. Proc Natl Acad Sci 97: 3292 3297.

Eshel I. 1983. Evolutionary and continuous stability. J Theor Biol 103: 99-111.

Eshel I, Motro U. 1981. Kin selection and strong evolutionary stability of mutual help. Theor Popul Biol 19: 420.

Fiegna F, Yu YT, Kadam SV, Velicer GJ. 2006. Evolution of an obligate social cheater to a superior cooperator. Nature 441: 310-314.

Fisher RA. 1930. The genetical theory of natural selection. Clarendon/Oxford University Press, Oxford.

Fisher HS, Hoekstra HE. 2010. Competition drives cooperation among closely related sperm of deer mice. Nature 463: 801-803.

Fletcher JA, Doebeli M. 2009. A simple and general explanation for the evolution of altruism. Proc R Soc Lond B Biol Sci 276: $13-19$.

Foster KR. 2004. Diminishing returns in social evolution: The not-so-tragic commons. J Evol Biol 17: 1058-1072.

Foster KR. 2006. Balancing synthesis with pluralism in sociobiology. J Evol Biol 19: 1394-1436.

Foster KR. 2008. Behavioral ecology: Altruism. In Encyclopedia of ecology (ed. SE Jorgensen and B Fath), pp. 154-159. Elsevier, Oxford.

Foster KR. 2010. Social behaviour in microorganisms. In Social behaviour: Genes, ecology and evolution (ed. T. Szekely et al.). Cambridge University Press, Cambridge. (In press.)

Foster KR, Ratnieks FL. 2001. Paternity, reproduction and conflict in vespine wasps: A model system for testing kin selection predictions. Behav Ecol Sociobiol 50: 1-8.

Foster KR, Wenseleers T. 2006. A general model for the evolution of mutualisms. J Evol Biol 19: 1283-1293.

Foster KR, Shaulsky G, Strassmann JE, Queller DC, Thompson CR. 2004. Pleiotropy as a mechanism to stabilize cooperation. Nature 431: 693-696.

Foster KR, Wenseleers T, Ratnieks FL. 2006a. Kin selection is the key to altruism. Trends Ecol Evol 21: 57-60.

Foster KR, Wenseleers T, Ratnieks FL, Queller DC. 2006b. There is nothing wrong with inclusive fitness. Trends Ecol Evol 21: 599-600.

Foster KR, Parkinson K, Thompson CR. 2007. What can microbial genetics teach sociobiology? Trends Genet 23: 74-80.

Frank SA. 1994. Kin selection and virulence in the evolution of protocells and parasites. Proc R Soc Lond B Biol Sci 258: 153.

Frank SA. 1995. Mutual policing and repression of competition in the evolution of cooperative groups. Nature 377: 520-522.

Frank SA. 1998. The foundations of social evolution: Monographs in behavior and ecology. Princeton University Press, Princeton, NJ

Gadagkar R. 1990. Evolution of eusociality: The advantage of assured fitness returns. Philos Trans R Soc Lond B Biol Sci 329: $17-25$.

Gardner A. 2009. Adaptation as organism design. Biol Lett 5: 861-864.

Gardner A, Foster KR. 2008. The evolution and ecology of cooperation: History and concepts. In Ecology of social evolution (ed. J Korb and J Heinze), pp. 1-35. Springer Verlag, Berlin.

Gardner A, Grafen A. 2009. Capturing the superorganism: A formal theory of group adaptation. $J$ Evol Biol 22: 659-671.

Gardner A, West SA. 2004. Spite and the scale of competition. $J$ Evol Biol 17: 1195-1203.

Gardner A, West SA. 2010. Greenbeards. Evolution 64: 25-38.

Gardner A, West SA, Buckling A. 2004. Bacteriocins, spite and virulence. Proc Biol Sci 271: 1529-1535.

Gardner A, West SA, Barton NH. 2006. The relation between multilocus population genetics and social evolution theory. $\mathrm{Am}$ Nat 169: 207-226.

Geritz SAH, Kisdi E, Meszéna G, Metz JAJ. 1998. Evolutionarily singular strategies and the adaptive growth and branching of the evolutionary tree. Evol Ecol 12: 35-57.

Gilbert OM, Foster KR, Mehdiabadi NJ, Strassmann JE, Queller DC. 2007. High relatedness maintains multicellular cooperation in a social amoeba by controlling cheater mutants. Proc Natl Acad Sci 104: 8913-8917.

Goodnight CJ. 1985. The influence of environmental variation on group and individual selection in a cress. Evolution 39: 545-558.

Goodnight CJ. 1990a. Experimental studies of community evolution. I. The response to selection at the community level. Evolution 44: 1614-1624.

Goodnight CJ. 1990b. Experimental studies of community evolution. II. The ecological basis of the response to community selection. Evolution 44: 1625-1636.

Goodnight CJ, Stevens L. 1997. Experimental studies of group selection: What do they tell us about group selection in nature? Am Nat 150: S59-S79.

Goodnight CJ, Schwartz JM, Stevens L. 1992. Contextual analysis of models of group selection, soft selection, hard selection, and the evolution of altruism. Am Nat 140: 743-761.

Greig D, Travisano M. 2004. The prisoner's dilemma and polymorphism in yeast SUC genes. Proc R Soc Lond B Biol Sci 271: S25-S26.

Griffin AS, West SA. 2003. Kin discrimination and the benefit of helping in cooperatively breeding vertebrates. Science 302: 634-636.

Griffin AS, West SA, Buckling A. 2004. Cooperation and competition in pathogenic bacteria. Nature 430: 1024-1027.

Hamilton WD. 1963. The evolution of altruistic behaviour. Am Nat 97: 354-356.

Hamilton WD. 1964. The genetical evolution of social behaviour (I \& II). J Theor Biol 7: 1-52.

Hamilton WD. 1967. Extraordinary sex ratios. Science 156: 477 488.

Hamilton WD. 1975. Innate social aptitudes in man: An approach from evolutionary genetics. In Biosocial anthropology (ed. R Fox), pp. 133-155. Wiley, New York.

Hamilton WD. 1987. Kinship, recognition, disease and intelligence: Constraints of social evolution. In Animal societies: Theories and facts (ed. Y Ito et al.), pp. 81-102. Japan Scientific Societies, Tokyo.

Hamilton WD. 1996. Narrow roads of gene land, Vol. 1. Freeman, New York.

Hardin G. 1968. The tragedy of the commons. Science 162: $1243-1244$.

Heinze J, d'Ettorre P. 2009. Honest and dishonest communication in social Hymenoptera. J Exp Biol 212: 1775-1779.

Heisler IL, Damuth J. 1987. A method for analyzing selection in hierarchically structured populations. Am Nat 130: 582-602.

Helanterä H, Strassmann JE, Carrillo J, Queller DC. 2009. Unicolonial ants: Where do they come from, what are they and where are they going? Trends Ecol Evol 24: 341-349.

Hughes WO, Oldroyd BP, Beekman M, Ratnieks FL. 2008. Ancestral monogamy shows kin selection is key to the evolution of eusociality. Science 320: 1213-1216.

Hunt JH, Amdam GV. 2005. Bivoltinism as an antecedent to eusociality in the paper wasp genus Polistes. Science 308: 264-267.

Hunt JH, Kensinger BJ, Kossuth JA, Henshaw MT, Norberg K, Wolschin F, Amdam GV. 2007. A diapause pathway underlies the gyne phenotype in Polistes wasps, revealing an evolutionary route to caste-containing insect societies. Proc Natl Acad Sci 104: 14020-14025.

Hurst LD, Atlan A, Bengtsson BO. 1996. Genetic conflicts. $Q$ Rev Biol 71: 317-364.

Johns PM, Howard KJ, Breisch NL, Rivera A, Thorne BL. 2009. Nonrelatives inherit colony resources in a primitive termite. Proc Natl Acad Sci 106: 17452-17456.

Keller L, Ross KG. 1998. Selfish genes: A green beard in the red 
fire ant. Nature 394: 573-575.

Kerr B, Neuhauser C, Bohannan BJM, Dean AM. 2006. Local migration promotes competitive restraint in a host-pathogen 'tragedy of the commons.' Nature 442: 75-78.

Korb J. 2006. Limited food induces nepotism in drywood termites. Biol Lett 2: 364-366.

Korb J. 2007. Workers of a drywood termite do not work. Front Zool 4: 7 .

Korb J, Heinze J. 2008. Ecology of social evolution. Springer, New York.

Korb J, Weil T, Hoffmann K, Foster KR, Rehli M. 2009. A gene necessary for reproductive suppression in termites. Science 324: 758 .

Lehmann L, Keller L. 2006. The evolution of cooperation and altruism: A general framework and a classification of models. J Evol Biol 19: 1365-1376.

Lehmann L., Keller L, Sumpter DJ. 2007a. The evolution of helping and harming on graphs: The return of the inclusive fitness effect. J Evol Biol 20: 2284-2295.

Lehmann L, Keller L, West S, Roze D. 2007b. Group selection and kin selection: Two concepts but one process. Proc Nat Acad Sci 104: 6736-6739.

Maynard Smith J. 1964. Group selection and kin selection. Nature 201: 1145-1147.

Maynard Smith J. 1975. Survival through suicide. New Sci 28: 496- 497.

Maynard Smith J. 1982. Evolution and the theory of games. Cambridge University Press, New York.

Maynard Smith J, Price GR. 1973. The logic of animal conflict. Nature 246: 15-18.

Mayr E. 1960. Where are we? Cold Spring Harbor Symp Quant Biol 24: 1-14.

Mehdiabadi NJ, Jack CN, Farnham TT, Platt TG, Kalla SE, Shaulsky G, Queller C, Strassmann JE. 2006. Social evolution: Kin preference in a social microbe. Nature 442: 881-882.

Merlo LM, Pepper JW, Reid BJ, Maley CC. 2006. Cancer as an evolutionary and ecological process. Nat Rev Cancer 6: 924 935.

Metz JAJ, Nisbet R, Geritz SAH. 1992. How should we define 'fitness' for general ecological scenarios? Trends Ecol Evol 7: 198-202.

Muir WM. 1996. Group selection for adaptation to multiple-hen cages: Selection program and direct responses. Poult Sci 75: 447-458.

Nadell CD, Xavier JB, Foster KR. 2009. The sociobiology of biofilms. FEMS Microbiol Rev 33: 206-224.

Nowak MA. 2006. Five rules for the evolution of cooperation. Science 314: 1560-1563.

Okasha S. 2006. Evolution and the levels of selection. Oxford University Press, New York.

Pizzari T, Foster KR. 2008. Sperm sociality: Cooperation, altruism, and spite. PLoS Biol 6: e130.

Price GR. 1970. Selection and covariance. Nature 227: 520-521.

Price GR. 1972. Extension of covariance selection mathematics. Ann Hum Genet 35: 455-458.

Queller DC. 1989. The evolution of eusociality-Reproductive head starts of workers. Proc Natl Acad Sci 86: 3224-3226.

Queller DC. 1992. Quantitative genetics, inclusive fitness, and group selection. Am Nat 139: 540-558.

Queller DC, Strassmann JE. 2009. Beyond society: The evolution of organismality. Philos Trans R Soc Lond B Biol Sci 364: 3143-3155.

Queller DC, Ponte E, Bozzaro S, Strassmann JE. 2003. Singlegene greenbeard effects in the social amoeba Dictyostelium discoideum. Science 299: 105-106.

Rankin DJ, Bargum K, Kokko H. 2007a. The tragedy of the commons in evolutionary biology. Trends Ecol Evol 22: 643-651.

Rankin DJ, López-Sepulcre A, Foster KR, Kokko H. 2007b. Species-level selection reduces selfishness through competitive exclusion. J Evol Biol 20: 1459-1468.

Ratnieks FLW. 1988. Reproductive harmony via mutual policing by workers in eusocial hymenoptera. Am Nat 132: 217-236.

Ratnieks FLW, Reeve HK. 1992. Conflict in single-queen hyme- nopteran societies: The structure of conflict and processes that reduce conflict in advanced eusocial species. J Theor Biol 158: 33-65.

Ratnieks FLW, Foster KR, Wenseleers T. 2006. Conflict resolution in insect societies. Annu Rev Entomol 51: 581-608.

Reeve HK, Holldobler B. 2007. The emergence of a superorganism through intergroup competition. Proc Natl Acad Sci 104: 9736-9740.

Reeve HK, Keller L. 1999. Levels of selection: Burying the unitsof-selection debate and unearthing the crucial new issues. In Levels of selection in evolution (ed. L Keller), pp. 3-14. Princeton University Press, Princeton, NJ.

Robinson GE. 1999. Integrative animal behaviour and sociogenomics. Trends Ecol Evol 14: 202-205.

Robinson GE, Grozinger CM, Whitfield CW. 2005. Sociogenomics: Social life in molecular terms. Nat Rev Genet 6: 257-270.

Santorelli LA, Thompson CRL, Villegas E, Svetz J, Dinh C, Parikh A, Sucgang R, Kuspa A, Strassmann JE, Queller DC, Shaulsky G. 2008. Facultative cheater mutants reveal the genetic complexity of cooperation in social amoebae. Nature 451: 11071110.

Schwartz M. 2000. Death of an altruist. Was the man who found the selfless gene too good for this world? Lingua Franca 10: 51-61.

Sherman PW, Seeley TD, Reeve HK. 1988. Parasites, pathogens, and polyandry in social hymenoptera. Am Nat 131: 602-610.

Shuker DM., Pen I, Duncan AB, Reece SE, West SA. 2005. Sex ratios under asymmetrical local mate competition: Theory and a test with parasitoid wasps. Am Nat 166: 301-316.

Shuker DM, Pen I, West SA. 2006. Sex ratios under asymmetrical local mate competition in the parasitoid wasp Nasonia vitripennis. Behav Ecol 17: 345-352.

Simpson SJ, Sword GA, Lorch PD, Couzin ID. 2006. Cannibal crickets on a forced march for protein and salt. Proc Natl Acad Sci 103: 4152-4156.

Smith CR, Toth AL, Suarez AV, Robinson GE. 2008. Genetic and genomic analyses of the division of labour in insect societies. Nat Rev Genet 9: 735-748.

Smith AA, Hölldober B, Liebig J. 2009. Cuticular hydrocarbons reliably identify cheaters and allow enforcement of altruism in a social insect. Curr Biol 19: 78-81.

Smukalla S, Caldara M, Pochet N, Beauvais A, Guadagnini S, Yan C, Vinces MD, Jansen A, Prevost MC, Latgé JP, et al. 2008. FLO1 is a variable green beard gene that drives biofilm-like cooperation in budding yeast. Cell 135: 726-737.

Sumpter DJT. 2006. The principles of collective animal behaviour. Philos Trans R Soc Lond B Biol Sci 361: 5-22.

Swenson W, Wilson DS, Elias R. 2000. Artificial ecosystem selection. Proc Natl Acad Sci 97: 9110-9114.

Taylor PD. 1996. Inclusive fitness arguments in genetic models of behaviour. J Math Biol 34: 654-674.

Trivers RL. 1971. The evolution of reciprocal altruism. $Q$ Rev Biol 46: $35-57$.

Trivers RL. 1974. Parent-offspring conflict. Am Zool 14: 249-264.

Trivers R. 1985. Social evolution. Benjamin/Cummings, Menlo Park, CA.

Velicer GJ, Kroos L, Lenski RE. 2000. Developmental cheating in the social bacterium Myxococcus xanthus. Nature 404: 598601.

Wade MJ. 1976. Group selection among laboratory populations of Tribolium. Proc Natl Acad Sci 73: 4604-4607.

Wade MJ. 1977. An experimental study of group selection. Evolution 31: 134-153.

Weinig C, Johnston JA, Willis CG, Maloof JN, Kohn J. 2007. Antagonistic multilevel selection on size and architecture in variable density settings. Evolution 61: 58-67.

Wells HG, Huxley JS, Wells GP. 1929. The science of life. Waverley, London.

Wenseleers T, Ratnieks FLW. 2004. Tragedy of the commons in Melipona bees. Proc R Soc Lond B Biol Sci 271: S310-S312.

Wenseleers T, Ratnieks FLW. 2006a. Comparative analysis of worker reproduction and policing in eusocial hymenoptera supports relatedness theory. Am Nat 168: E163-E179. 
Wenseleers T, Ratnieks FL. 2006b. Enforced altruism in insect societies. Nature 444: 50.

Wenseleers T, Ratnieks FLW, Billen J. 2003. Caste fate conflict in swarm-founding social hymenoptera: An inclusive fitness analysis. J Evol Biol 16: 647-658.

Wenseleers T, Hart AG, Ratnieks FLW. 2004a. When resistance is useless: Policing and the evolution of reproductive acquiescence in insect societies. Am Nat 164: E154-E167.

Wenseleers T, Helanterä H, Hart AG, Ratnieks FLW. 2004b. Worker reproduction and policing in insect societies: An ESS analysis. J Evol Biol 17: 1035-1047.

Wenseleers T, Gardner A, Foster KR. 2010. Social evolution theory: A review of methods and approaches. In Social behaviour: Genes, ecology and evolution (ed. T Szekely et al.). Cambridge University Press, Cambridge. (In press.)

Werren JH. 1980. Sex-ratio adaptations to local mate competition in a parasitic wasp. Science 208: 1157-1159.

West SA, Griffin AS, Gardner A, Diggle SP. 2006. Social evolution theory for microorganisms. Nat Rev Microbiol 4: 597-607.

West SA, Griffin AS, Gardner A. 2007. Social semantics: Altruism, cooperation, mutualism, strong reciprocity and group selection. J Evol Biol 20: 415-432.

West SA, Griffin AS, Gardner A. 2008. Social semantics: How useful has group selection been? J Evol Biol 21: 374-385.

Wheeler WM. 1911. The ant-colony as an organism. J Morphol 22: $307-325$.

Williams GC. 1966. Adaptation and natural selection: A critique of some current evolutionary thought. Princeton University Press, Princeton, NJ.
Williams HTP, Lenton TM. 2008. Environmental regulation in a network of simulated microbial ecosystems. Proc Natl Acad Sci 105: 10432-10437.

Wilson EO. 1971. The insect societies. Harvard University Press, Cambridge, MA.

Wilson DS. 1975a. A theory of group selection. Proc Natl Acad Sci 72: 143-146.

Wilson EO. 1975b. Sociobiology: The new synthesis. Harvard University Press, Cambridge, MA.

Wilson DS. 1990. Weak altruism, strong group selection. Oikos 59: $135-140$.

Wilson EO. 2005. Kin selection as the key to altruism: Its rise and fall. Soc Res 72: 159-168.

Wilson DS. 2008a. Social semantics: Toward a genuine pluralism in the study of social behaviour. J Evol Biol 21: 368-373.

Wilson EO. 2008b. One giant leap: How insects achieved altruism and colonial life. BioScience 58: 17-25.

Wilson EO, Holldobler B. 2005. Eusociality: Origin and consequences. Proc Natl Acad Sci 102: 13367-13371.

Wilson DS, Wilson EO. 2007. Rethinking the theoretical foundation of sociobiology. $Q$ Rev Biol 82: 327-348.

Wilson DS, Wilson EO. 2008. Evolution "for the good of the group." Am Sci 96: 380-389.

Wynne-Edwards VC. 1962. Animal dispersal in relation to social behaviour. Oliver and Boyd, Edinburgh.

Xavier JB, Martinez-Garcia E, Foster KR. 2009. Social evolution of spatial patterns in bacterial biofilms: When conflict drives disorder. Am Nat 174: 1-12. 


\title{
$8_{\mathrm{CSH}}^{\infty} \mathrm{Cold}$ Spring Harbor Symposia SYMPOSIA on Quantitative Biology
}

\section{A Defense of Sociobiology}

\author{
K.R. Foster
}

Cold Spring Harb Symp Quant Biol 2009 74: 403-418 originally published online April 7, 2010 Access the most recent version at doi:10.1101/sqb.2009.74.041

References This article cites 138 articles, 26 of which can be accessed free at: http://symposium.cshlp.org/content/74/403.full.html\#ref-list-1

License

Email Alerting Receive free email alerts when new articles cite this article - sign up in the box at the Service top right corner of the article or click here.

To subscribe to Cold Spring Harbor Symposia on Quantitative Biology go to: http://symposium.cshlp.org/subscriptions 